\title{
Rede de atenção à saúde de gestantes e puérperas: percepções de trabalhadores da saúde
}

\author{
Health care network for pregnant and puerperal women: perceptions of health workers \\ Red de salud para mujeres embarazadas y puerperales: percepciones de los trabajadores de salud
}

\section{RESUMO}

Objetivo: compreender a percepção que os trabalhadores da saúde da família possuem acerca da rede de atenção à saúde no pré-natal e puerpério. Método: pesquisa qualitativa desenvolvida de março a abril de 2019, com oito trabalhadores da saúde que atuam em uma Estratégia Saúde da Família. Para a coleta dos dados, utilizou-se a entrevista semiestruturada. Os dados foram analisados segundo a análise temática de conteúdo. Resultados: emergiram duas categorias: percepção dos trabalhadores acerca da organização da Rede de Atenção à Saúde no pré-natal e puerpério e Serviços que integram a rede de atenção à saúde das gestantes e puérperas. Conclusão: há muitas fragilidades na rede de atenção à saúde, que englobam a comunicação entre os diferentes serviços, a existência de uma comunicação informal e a dificuldade de acesso dessa população à serviços de saúde essenciais, o que interfere na integralidade do cuidado.

DESCRITORES: Enfermagem; Atenção primária à saúde; Serviços de saúde; Gravidez; Período pós-parto.

\section{ABSTRACT}

Objective: to understand the perception that family health workers have about the health care network in prenatal and postpartum periods. Method: qualitative research developed from March to April 2019, with eight health workers who work in a Family Health Strategy. For data collection, a semi-structured interview was used. Data were analyzed according to thematic content analysis. Results: two categories emerged: workers' perception about the organization of the Health Care Network in prenatal and puerperium and Services that are part of the health care network of pregnant and postpartum women. Final considerations: there are many weaknesses in the health care network, which include communication between different services, the existence of informal communication and the difficulty of this population's access to essential health services, which interferes with the integrality of care.

DESCRIPTORS: Nursing; Primary health care; Health services; Pregnancy; Postpartum period

\section{RESUMEN}

OObjetivo: comprender la percepción que tienen los trabajadores de salud de la familia sobre la red asistencial en el período prenatal y posparto. Método: investigación cualitativa realizada de marzo a abril de 2019, con ocho trabajadores de la salud que laboran en una Estrategia de Salud de la Familia. Para la recolección de datos se utilizó una entrevista semiestructurada. Los datos se analizaron de acuerdo con el análisis de contenido temático. Resultados: surgieron dos categorías: percepción de los trabajadores sobre la organización de la Red de Atención de Salud en el prenatal y puerperio y los Servicios que forman parte de la red de atención de la salud de la mujer gestante y posparto. Consideraciones finales: existen muchas debilidades en la red asistencial, que incluyen la comunicación entre diferentes servicios, la existencia de comunicación informal y la dificultad de acceso de esta población a los servicios esenciales de salud, lo que interfiere con la atención integral.

DESCRIPTORES: Enfermería; Atención primaria de salud; Servicios de salud; embarazo; Periodo posparto.

RECEBIDO EM: 08/06/21 APROVADO EM: 14/06/21

\section{Keity Laís Siepmann Soccol}

Universidade Franciscana (UFN)

Enfermeira. Doutora em enfermagem. Docente do curso de enfermagem e Mestrado Profissional Saúde Materno Infantil. ORCID: 0000-0002-7071-3124

\section{Mara Regina Caino Teixeira Marchiori}

Universidade Franciscana (UFN)

Enfermeira. Doutora em enfermagem. Docente do curso de enfermagem e Mestrado Profissional Saúde Materno Infantil. ORCID: 0000-0001-9412-7755

\author{
Naiana Oliveira Dos Santos \\ Universidade Franciscana (UFN) \\ Enfermeira. Doutora em enfermagem. Docente do curso de enfermagem. \\ ORCID: 0000-0002-5439-2607
}


Bruna Dedavid Da Rocha

Universidade Franciscana.

Enfermeira. Mestra em Saúde Materno Infantil pela Universidade Franciscana.

ORCID: 0000-0003-4880-4676

\section{INTRODUÇÃO}

$\mathbf{N}$ os últimos anos ocorreram um avanço quanto as políticas públicas orientadas para a atenção integral à saúde da mulher. Essas políticas tem como premissa garantir os direitos sexuais e reprodutivos, a redução dos indicadores de partos cesarianas, o estímulo às boas práticas na assistência à gestantes e às puérperas, bem como reduzir a mortalidade materna(1).

Nesse sentido, em 1983 o Ministério da Saúde da Saúde criou o Programa de Assistência Integral à Saúde da Mulher (PAISM). Posteriormente, no ano de 2003, esse Programa foi reformulado e, assim aprovado como Política Nacional de Atenção Integral à Saúde da Mulher (PNAISM), que tem como princípios a integralidade e a promoção da saúde, recomenda a consolidação de direitos sexuais e reprodutivos e o avanço da atenção obstétrica e preconiza o planejamento familiar(2).

A criação de alguns programas como a Rede Cegonha, o Programa de Humanização do Parto e Nascimento (PHPN) e a Vigilância de Óbitos de Mulheres em Idade Fértil foram instituídos para efetivar a Política Nacional de Atenção Integral à Saúde da Mulher (PNAISM)(2) e fortalecer o ordenamento da Rede de Atenção à Saúde (RAS), no Sistema Único de Saúde (SUS), na qual tem a Atenção Primária à Saúde (APS) como protagonista na gestão do cuidado(3).

A APS deve ser prioritariamente o ponto de atenção e porta de entrada no sistema, sendo também a responsável por ordenar os fluxos e contrafluxos da população nos diferentes pontos de atenção(4). Em se tratando de serviços que se configuram como porta de entrada na APS, a Estratégia Saúde da Família (ESF) assume um modelo de assistência direcionado para o desenvolvimento de ações individuais e coletivas em
Em 1983 o

Ministério da

Saúde da Saúde

criou o Programa

de Assistência

Integral à Saúde da

Mulher (PAISM).

Posteriormente,

no ano de 2003,

esse Programa foi

reformulado e,

assim aprovado

como Política

Nacional de Atenção

Integral à Saúde da

Mulher (PNAISM)

[...] base territorial, que assiste e promove o atendimento do pré-natal humanizado na $\operatorname{RAS}(5)$.

A organização das RAS possibilita um cuidado integral que atenda às necessidades de saúde da população. Por isso, conhecer a trajetória assistencial das pessoas na RAS permite ampliar o olhar acerca das dificuldades, desde a APS até a atenção hospitalar, e sobre o caminho percorrido na busca por cuidados(6). O acesso aos serviços de saúde colaboram para reduzir a mortalidade materna bem como, para a garantia da atenção integral à saúde da mulher (7).

Conhecer os serviços da RAS e o modo como ocorre a sua dinâmica permite identificar as fragilidades que possam existir na atenção ao pré-natal, e apontar possíveis estratégias para a efetividade do cuidado que é oferecido no acompanhamento ao pré-natal(8) e no puerpério. Também, apontará estratégias de mudança no processo de trabalho e gestão dos serviços de APS.

Diante do exposto, este estudo teve como questão de pesquisa: como os trabalhadores da saúde da família percebem a RAS no pré-natal e puerpério? O objetivo é compreender a percepção que os trabalhadores da saúde da família possuem acerca da RAS no pré-natal e puerpério.

\section{MÉTODOS}

Trata-se de uma pesquisa com abordagem qualitativa, que foi desenvolvida com oito trabalhadores da saúde que atuam em uma Estratégia Saúde da Família (ESF), localizada em um município do Rio Grande do Sul, Brasil.

Todos os trabalhadores de saúde da equipe que realizavam cuidados a gestantes e puérperas foram convidados a participar da pesquisa. No entanto, foram excluídos aqueles que estivessem afastados por licença médica no momento da coleta das infor- 
mações.

Para a coleta das informações utilizou-se da entrevista semiestruturada, que foi realizada individualmente nos meses de março e abril de 2019. As entrevistas foram realizadas em uma sala reservada na ESF de acordo com a disponibilidade de cada trabalhador, assim foram gravadas por um gravador de áudio e, posteriormente transcritas e analisadas de acordo com a Análise Temática, que compreendeu as seguintes etapas: pré-análise, exploração do material e tratamento dos resultados obtidos e interpretação (9). As entrevistas tiveram duração entre vinte e seis e trinta e quatro minutos.

Para a entrevista foram utilizadas as seguintes questões norteadoras: Como você percebe a Rede de Atenção à Saúde das gestantes e puérperas? Quais são os serviços que você aciona ou encaminha na Rede de Atenção à Saúde? E como você percebe a comunicação com esses serviços?

Para garantir o anonimato dos profissionais de saúde, adotaram-se as letras iniciais de "TNS" (trabalhador de nível superior) e de "TNM" (trabalhador de nível médio), seguidas de um número que corresponde à ordem em que as entrevistas foram realizadas.

A pesquisa seguiu os princípios éticos da Resolução No 466/12 do Conselho Nacional de Saúde, que regulamenta as normas para realização de pesquisas envolvendo seres humanos. Todos os participantes assinaram o Termo de Consentimento Livre e Esclarecido que continha informações referentes ao desenvolvimento da pesquisa. A pesquisa foi aprovada pelo Comitê de Ética em Pesquisa da Universidade Franciscana, sob o parecer No 3.019.307, CAAE 02373018.4.0000.5306, que foi emitido no dia 13 de novembro de 2018.

\section{RESULTADOS}

A partir da análise temática dos dados emergiram duas categorias: Percepção dos trabalhadores acerca da organização da RAS no pré-natal e puerpério e Serviços que integram a Rede de Atenção à Saúde das gestantes e puérperas.

Percepção dos trabalhadores acerca da organização da RAS no pré-natal e puerpério

Os trabalhadores da saúde percebem que há fragilidades na comunicação entre os diversos pontos da RAS, que são expressas devido não ter um sistema de informação compartilhado nos serviços de diferentes complexidades:

O sistema informatizado não tem relação com o Hospital Universitário. Então a gente vai pelo que elas (gestantes/puérperas) falam ou pelo que a gente consegue captar. Falta essa ligação entre a rede e essa conversa fica mais no impessoal. (TNS 3)

$A$ rede é bem precária, bem difícil. $E u$ venho de outra realidade que era bem diferente disso, mas a gente pelo menos usava o mesmo Sistema $e$ conseguia ter um acompanhamento. (TNS 4)

Os trabalhadores referem que há pouca resolutividade e agilidade quando há a necessidade de marcar algum exame:

A gente pede ultrassom no início da gestação, só que se eles acham que ela está com menos de 12 semanas e não passa na regulação. Falta um pouco mais de agilidade e de resolutividade das situaçóes, de não esperar tanto ou não ser tanto encaminhamento (TNS 2).

A gente não consegue detectar nenhuma sindrome durante a gestação pela qualidade do ultrassom. $E$ isso tem diferença comparada ao ultrassom realizado no particular ( TNS 3).

A percepção que os trabalhadores possuem acerca da RAS às gestantes e puérperas é de que as necessidades de saúde não são atendidas. Ainda, há à falta de comunicação decorrente da insuficiência de um sistema de informação que integre todos os serviços.
Serviços que integram a Rede de Atenção à Saúde das gestantes e puérperas

A presente categoria expressa quais são os serviços que os trabalhadores encami-

Os trabalhadores da

saúde percebem que

há fragilidades na

comunicação entre

os diversos pontos

da RAS, que são

expressas devido

não ter um sistema

de informação

compartilhado

nos serviços

de diferentes

complexidades

nham as gestantes e puérperas na RAS. No que se refere ao pré-natal odontológico, evidencia-se que existe dificuldade de acesso das gestantes à RAS, pois as mesmas precisam buscar assistência fora do seu território. 
A gente não tem dentista aqui na Unidade e isso é uma falta, mas tem a referência que é no Pronto- $A$ tendimento Municipal. Elas são referenciadas para lá. É mais difícil didas principalmente em serviços de urgência e emergência municipal ou quando tem esse profissional disponível na RAS:

O psicólogo eu não tive muitas experiências boas, porque às vezes que eu tentei marcar consulta não tinha. Pelo que ouvi no município não tem psicólogo. (TNS 3)

Já encaminhei várias vezes para o P.A. Eles têm atendimento psicológico para as gestantes e puérperas. Então o que mais faz falta aqui é isso. (TNS1)

Quando os trabalhadores identificam algum transtorno mental eles encaminham as gestantes e puérperas para o Centro de Atenção Psicossocial (CAPS):

\section{O psicólogo eu}

\section{não tive muitas}

experiências boas,

porque às vezes que

eu tentei marcar

consulta não tinha

Pelo que ouvi no

município não tem

psicólogo

porque elas têm que se deslocar até lá. (TNS2)

No que tange às necessidades psicológicas das gestantes e puérperas, elas são aten-
Quando precisa fazer o encaminhamento para um CAPS, é feito pelo médico. Eles vão com a cartinha $e$ fazem o atendimento lá. (TNS 3)

Outro serviço da RAS que os trabalhadores encaminham as gestantes e puérperas em situação ou suspeita de vulnerabilidade social é o Centro de Referência de Assistência Social (CRAS):

Quando a gente vê que tem necessidade de bolsa familia dai a gente encaminha para o CRAS. (TNM 2)

Eu acabo dependendo do CRAS porque muitas vezes eu encontro elas em vulnerabilidade. Eu aciono, porque muitas vezes elas precisam de outro suporte e até porque tem essa criança pode estar em risco. (TNS 4)

Para garantir a assistência às gestantes que possuem transtornos relacionados ao uso de drogas ou outras patologias que possam comprometer a saúde e a integridade fetal, os trabalhadores solicitam assistência do Conselho Tutelar:

Gestantes que tem problemas de

drogas, tem problemas de sifilis $e$ IST's (infecções sexualmente transmissíveis) na área, e a gente tem que estar sempre muito bem articulado com a equipe de enfermagem $e$ com os agentes de saúde. E chamar as faltosas para acionar o conselho tutelar, CRAS ou CAPS. (TNS 2)

Com as gestantes adolescentes se ela não veio no posto fazer o pré-natal, primeira coisa que eu faço é ameaçar ela com o Conselho Tutelar. (TNM 3)

Os trabalhadores expressam que Conselho Tutelar não é efetivo na RAS e que as denúncias não ocorrem de modo anônimo:

O Conselho Tutelar não funciona como poderia funcionar. Porque tu faz uma denúncia, mas os usuários sabem que foi tu, porque eles (os profissionais do Conselho Tutelar) falam. (TNM 3)

O Conselho chega lá e diz: "Fulana te denunciou". Eu particularmente acho que Conselho não funciona nessa cidade. (TNM 4)

Em casos de urgências ou emergências, as gestantes e puérperas são encaminhadas ao Pronto-Atendimento Municipal ou para a Unidade de Pronto Atendimento, que por vezes ocorre com auxílio do Serviço de Atendimento Móvel de Urgência:

Entra em contato com Pronto-Atendimento ou Unidade de Pronto Atendimento. E quando a pessoa chega ruim, ele chama um transporte (SAMU), e é bem tranquilo. (TNM 1)

As gestantes e puérperas peregrinam em diversos pontos da RAS. No entanto, esses serviços se mostram insuficientes para atender as necessidades de saúde delas.

\section{DISCUSSÃO}


A utilização do serviço de saúde pelas gestantes como referido pelos trabalhadores, e a demora na realização e resultados dos exames necessários, pode ocasionar lacunas no acompanhamento da gestação e no desenvolvimento da criança. A não realização de exames dificulta os diagnósticos precoces e o tratamento de complicações na gravidez(10). Esse dado confirma a falha na implantação das redes de apoio, gerando necessidade de reestruturação dos serviços disponíveis na rede, a fim de acolher de forma integral a população de gestantes, puérperas e crianças (11).

As ações realizadas na rede de atenção pela equipe de saúde, nas etapas do ciclo gravídico-puerperal, devem levar em consideração as formas de inserção social da mulher na comunidade adscrita da unidade de saúde, no intuito de alcançar um cuidado integral(12).

$\mathrm{O}$ acesso a consultas, exames e medicamentos foi apontado como outro indicador de qualidade na atenção, pois favorece, inclusive, o início precoce do acompanhamento pré-natal na atenção primária(8). Em relação ao acesso e utilização de serviços odontológicos por gestantes, pesquisa(13) demonstra baixa adesão ao pré-natal odontológico já que foram observados como principais fatores complicadores o acesso e utilização desses serviços, que estão relacionados aos aspectos culturais, educacionais e socioeconômicos. A baixa cobertura de pré-natal odontológico é uma realidade presente na atenção básica de saúde de muitos serviços no Brasil, e tem diversas causas envolvidas(14).

Em relação à atenção psicossocial, a literatura aponta que é importante discutir sobre a saúde mental da mulher, buscando atender de modo integral a saúde mental da mulher(15). Nesse sentido, a RAS pre-
Uma atenção

qualificada pré-

natal e no puerpério

ocorre por meio

da incorporação

de condutas

acolhedoras e

do fácil acesso a

serviços de saúde

de qualidade, com

ações que integrem

todos os níveis da

atenção: promoção,

prevenção e

assistência à saúde

da gestante e do

recém-nascido

cisa atender as demandas de saúde mental de modo resolutivo e em diferentes pontos sem que haja a necessidade dessas mulheres de buscar assistência em locais distantes de seu território.

O cuidado à saúde da mulher deve ocorrer de forma longitudinal, assim, tem-se a necessidade de qualificar tais ações a fim de acompanhar a mulher em todas as fases da gestação e do puerpério. Há evidências de que o cuidado a gestantes e puérperas necessita de qualificação da gestão e assistência nos serviços de saúde, superação do modelo biomédico tecnicista, contribuindo assim para a melhoria da saúde da mulher(16).

Uma atenção qualificada pré-natal e no puerpério ocorre por meio da incorporação de condutas acolhedoras e do fácil acesso a serviços de saúde de qualidade, com ações que integrem todos os níveis da atenção: promoção, prevenção e assistência à saúde da gestante e do recém-nascido(17).

\section{CONCLUSÃO}

Esse estudo evidenciou que há diversas fragilidades na RAS de gestantes e puérperas, que vão desde a comunicação entre os diferentes serviços, do difícil acesso ou por não ter disponibilidade na RAS, o que compromete a integralidade do cuidado e dificulta o processo de trabalho. Assim, são necessários investimentos no que tange à implementação dos sistemas de informação e um olhar atento da gestão quanto às necessidades de saúde que não vem sendo atendidas.

Sugere-se o desenvolvimento de estudos que envolvam os gestores dos serviços de atenção básica para que possam ser apontadas melhorias em prol de uma comunicação efetiva e para que haja a elaboração de estratégias para garantir uma assistência de qualidade e às gestantes e puérperas.

\section{REFERÊNCIAS}

1. Brasil. Ministério da Saúde. Política Nacional De Atenção Integral À Saúde Da Mulher: princípios e Diretrizes. [Internet]. Brasília (DF): 2011. Disponivel em: http://bvsms.saude.gov.br/bvs/publicacoes/ politica_nacional_mulher_principios_diretrizes.pdf

2. Brasil. Ministério da Saúde. Política Nacional de Atenção Integral à Saúde da Mulher: Princípios e Diretrizes. [Internet]. Brasília (DF):
2004. Disponivel em: http://bvsms.saude.gov.br/bvs/publicacoes/ politica_nac_atencao_mulher.pdf

3.Brasil. Ministério da Saúde. Humanização do parto e do nascimento. [Internet]. Brasília (DF): 2014. Disponível em: http://www.redehumanizasus.net/sites/default/files/caderno_humanizasus_v4_humanizacao_parto.pdf 


\section{REFERÊNCIAS}

4. Brasil. Ministério da Saúde. Portaria n. 2.436 de 21 de setembro de 2017. Aprova a Política Nacional de Atenção Básica estabelecendo a revisão de diretrizes para a organização da Atenção Básica, no âmbito do Sistema Único de Saúde (SUS). Brasília (DF): 2017. Disponivel em: https://bvsms.saude.gov.br/bvs/saudelegis/gm/2017/ prt2436_22_09_2017.html

5.Silva AA, Jardim MJA, Rios CTF, Fonseca LMB, Coimbra LC. Pré-natal da gestante de risco habitual: potencialidades e fragilidades. Rev. Enferm. UFSM. 2019;9(e15):1-20.

6.Galvão JR, Almeida PF, Santos AM, Bousquat A. Percursos e obstáculos na Rede de Atenção à Saúde: trajetórias assistenciais de mulheres em região de saúde do Nordeste brasileiro. Cad. Saúde Pública. 2019;35(12):e00004119.

7.Baratieri T, Natal S. Ações do programa de puerpério na atenção primária: uma revisão integrativa. Cien Saude Colet. 2019;24(11):4227-4238.

8.Sanine PR, Venancio SI, Silva FLG, Aratani N, Moita MLG, Tanaka OY. Atenção ao pré-natal de gestantes de risco e fatores associados no Município de São Paulo, Brasil. Cad. Saúde Pública. 2019; 35(10):e00103118.

9.Minayo MCS. O desafio do conhecimento: pesquisa qualitativa em saúde. $14^{\mathrm{a}}$ ed. São Paulo: Hucitec, 2014.

10. Diógenes IV, Evangelista BP, Araújo MJAM, Medeiros MF, de Freitas KML, Duarte RB. Assistência pré-natal conforme as diretrizes da Rede Cegonha em um município cearense. Saúde Coletiva (Barueri).2021;11(66):6381-6392.
11.Almeida AC, Mendes LC, Sad IR, Ramos EG, Fonseca VM, Peixoto MVM. Uso de instrumento de acompanhamento do crescimento e desenvolvimento da criança no Brasil: revisão sistemática de literatura. Rev Paul Pediatr. 2016;34(1):122-31.

12.Andrade RD, Santos JS, Maia MAC, Mello DF. Fatores relacionados à saúde da mulher no puerpério e repercussões na saúde da criança. Esc Anna Nery. 2015;19(1):181-6.

13.Silva CC, Savian CM, Prevedello BP, Zamberlan C, Dalpian DM, Santos BZ. Acesso e utilização de serviços odontológicos por gestantes: revisão integrativa de literatura. Ciênc. saúde coletiva. 2020; 25(3): 827-835.

14. Júnior DJK, Marmitt LP, Cesar JA. Não realização de consulta odontológica entre gestantes no extremo sul do Brasil: um estudo de base populacional. Ciência \& Saúde Coletiva. 2019;24(10):38893896.

15.Teixeira CS, Barbosa TL, Marangoni VSL, Neves ALM das, Therense M. Aspectos da gestação e puerpério de mulheres com transtornos mentais. Rev enferm UFPE on line. 2019;13:e239705. DOI: https://doi.org/10.5205/1981- 8963.2019.239705

16.Corrêa MSM, Feliciano KVO, Pedrosa EN. Souza Al. Acolhimento no cuidado à saúde da mulher no puerpério. Cad Saúde Pública. 2017; 33(3):1-12.

17.Lima SDS, Silva LCS, Santos MV, Martins JP, Oliveira MC, Brasileiro ME. HIV na gestação: pré-natal, parto e puerpério. Ciência \& Saúde. 2017;10(1):56-61. D 